\title{
NATURALISTIC AND CULTURAL FOUNDATIONS FOR A MORE EFFECTIVE INTERNATIONAL LAW*
}

\author{
F. S. C. NORTHROPT
}

INTERNATIONAL like domestic law must face the difficult question of norms. Without common norms between the nations and the cultures of the world there can be no effective international law. How are such universal norms for an effective international law to be found?

Contemporary developments in the social sciences and in the philosophy of natural science indicate that there are two sources. One is in the norms common to the diverse cultures of the world. The other is in scientifically verified philosophy of nature. The former source happens to be intimately connected with the latter.

It has been suggested elsewhere ${ }^{x}$ that the philosophy of nature as given content by the epistemologically analyzed, empirically verified theory of natural science can be used as a criterion of those ethical and legal norms which are universal and hence of the character required to undergird a more effective international law. It is the purpose of this paper (1) to show that this is the method of ethical and legal science of the traditional Orient and of the classical West up to at least the time of Kant; (2) to specify in greater detail what the method requires and how it proceeds; and (3) to point out that a new contemporary positive international law rooted in such empirically verified, universally valid norms has a chance of being effective since it meets the crucial criterion of effective law of the great sociologist of law, Ehrlich.

By an empirically verified science and philosophy of nature we shall mean one whose basic assumptions are confirmed either (a) directly or (b) indirectly through their deductive consequences, by appeal to data given with immediacy. This inclusion of directly verified theory permits us, as the sequel will show, to regard Oriental philosophy as empirically verified scientific knowledge, even though it differs from the experimentally confirmed, deductively formulated type of science and philosophy that arose with, and has grown in vitality since the time of the Ancient Greeks in the

* The author is indebted to the Viking Fund for a grant which makes possible this and other research in this field. The YALE LAw Joursal is indebted to Ruth Nanda Anshen, the Editor, and to Harper \& Bros., the publishers, of the farthcoming volume on ethics, in the Science of Culture Series, from which portions of this article are taken.

† Sterling Professor of Philosophy and Law, Yale Law School.

1. F. S. C. Northrop, The Meeting of EAST aNd West (hereafter referred to as MEW) cc. VIII, XII, XIII (1946) ; Northrop, LogIC of THE Sciences AND TIIE HUMrANITIES (hereafter referred to as LSH) c. XXII and especially pp. 359-60 (1947); Jurisprudence in the Law School Curriculum, 1 J. LEGAL EDuc. $482-94$ (1949). 
West, and which, as Albert Einstein and others have shown, ${ }^{2}$ is only indirectly verified.

Verification of a scientific theory is indirect if its basic assumptions refer to entities such as electrons which cannot be directly observed and if consequently the theory can be tested empirically only indirectly by way of theorems which are deduced from its basic assumptions. Then the logic of verification takes on the following form of the hypothetical syllogism: If $A$ (the unobservable postulated scientific objects) then $B$ (the deduced theorem or theorems). $B$ is the case. Therefore $A$ is the case.

As is well known, such an argument of the hypothetical syllogism commits the formal fallacy of affirming the consequent. What follows is not that a theory verified in this manner is false and should be rejected-quite the contrary, since the argument tells us that the implication of the theory has been confirmed. What follows instead is merely the warning that the uniqueness of the theory has not been established. In other words, from the fact that $A$ implies $B$ which is directly verified to be the case, it does not follow that $A$ is the only theory from which can be deduced the directly and experimentally verified fact described by $B$. Hence, while indirect verification confirms what one would expect if the theory in question is true and hence warrants our retaining the theory, the presence of the fallacy of affirming the consequent involved in such a logic of verification tells us also that the theory must be held tentatively with the mind open to other theoretical possibilities and with a willingness to reject the theory the moment any empirical fact turns up which is contrary to any of its deduced theorems.

Verification of a theory is direct when its basic assumptions refer only to entities and relations which are immediately apprehensible, thereby permitting its postulates themselves rather than merely some of its deduced theorems to be empirically tested. Curiously enough, it is Oriental rather than Western science and philosophy which meets this more certain and stringent test for empirical verification. Thus there is a sense in which Oriental philosophy is not merely as scientific as, but even more scientific than that of the West. Certainly, no science or philosophy can be more scientific than one which insists upon direct verification of its basic assumptions.

\section{The Ethical and Legal Method of the Orient}

The most widely accepted system of Hindu philosophy is Vedānta. The fundamental concept in this philosophy is Brahman. Of Brahman, two things are asserted: (1) Brahman, which is the cosmical principle in nature, is identical with Atman, which is the psychical principle in the self.

2. See my paper, Einstein's Conception of Science, in Albert Eristem: PurLosopher-Scientist, 7 The Library of Living Philosopirers (Schilpp ed. 1949); also Northrop, LSH, op. cit. supra note 1, c. XII; and Heney MLArgenau, The Nature of Physical Reality (1950). 
(2) Brahman is known by immediate apprehension. The first of these two assertions assures us that Brahman refers to nature and hence is a concept in the philosophy of nature. The second assertion guarantees that Brahman is verified directly and denotatively by immediate apprehension.

In all Buddhist philosophical systems, the major concept is Nirvāna or Suchness or the Void. Again we are told that this important factor in knowledge embraces nature as well as man and is known only with immediacy. Hence its verification is direct. In fact Nirvāna and Brahman alike embrace not merely nature and man as an object of knowledge in nature but also man as the determinate particular subjective knower of nature.

In China the three major philosophies of indigenous origin are Taoism, Confucianism and Chan or Zen Buddhism. Although Buddhism arose in India, Chan or Zen Buddhism, as Professor D. T. Suzuki has emphasized, is a creation of the Chinese. That Chan Buddhism is equally naturalistic is shown by the setting of its monasteries in the mountains, the communion with nature of its practitioners, and its naturalistic intermixture with Taoism in Chinese landscape painting. ${ }^{3}$ Only in the case of Confucianism might it seem that Chinese philosophy is an exception to the traditional rule that ethical and legal norms are to find their verification in nature. This exception is, however, a mere seeming. If the Confucian sages are asked why their particular norms for social and personal behavior are the true ones, the answer is that these norms put man in harmony with nature. ${ }^{4}$

This recursive reference of Confucian personal and legal ethical norms to one's directly verified knowledge of nature has been obscured by many students of Confucian ethics because they have neglected to reconstruct the very technical conception of nature referring to the directly sensed colors of the different seasons of the yearly cycle of nature and to the natural differences between types of men. The latter differences, like sensed sequences of colors designating spring, summer, fall and winter, are regarded as characteristics of groups of individuals which are quite independent of cultural beliefs or of culturally conditioned and relative norms, much after the manner of the different natural personality types and their role with respect to ethics, in the studies of Charles W. Morris in our own time. Good personal and social conduct, according to the Confucian Chinese, is that behavior of individuals and that ordering of social relations which takes into account these directly sensed sequences of the seasons and the empirically evident natural diversities of human nature. As the Neo-Confucianist Hu Yan Mung, quoting from the Confucianist Siun Tseu, said of a specific ethical and legal social norm, "This rule is called 'equality con-

3. See Plates XIII and XIV in Northrop, MEW, supra note 1 , at 406.

4. For evidence supporting this point and a designation of its precise content and meaning, see Gray L. Dorsey's investigation of the source of verification of Confucian Chinese legal norms in his chapter, Two Objective Bases for a World-Wide Legal Order, Ideologrcal Differences and World Order (F. S. C. Northrop ed. 1949). 
formable to "natural" differentiation' or 'union without injury to "human" diversity." "s

The connection between the ethical and legal ordering of people in society and empirically grounded conceptions of nature in Confucian Chinese culture is even more explicit. Granet has shown that when the early Chinese shifted from a two-fold conception of natural phenomena expressed in terms of yin yang to a four-fold conception of nature based on the four-sensed directions projecting out from the perceiver their rules for the proper ethical ordering of people in man-directed society underwent a corresponding change. ${ }^{6}$

This naturalistic criterion for the validity of ethical norms in traditional Oriental philosophy and culture shows even more markedly when we look at the practical behavior which these norms prescribe. The Chinese painting which gives the greatest expression to Buddhist and Taoist religious and other human values is the naturalistic landscape painting. In this painting man is usually portrayed as either a relatively insignificant item in one corner of the picture or a sage sitting under a tree immediately apprehending the all-embracing immediacy of nature within which he is immersed. It is a commonplace that the Hindu of the morally highest caste, after establishing his family and training his son to succeed him, is required, as an ethical prescription by the norms of his philosophical and religious beliefs, to withdraw from cultural institutions and conventional family and social relations and return to the pristine relation to nature of a forest hermit and an itinerant seer, making a pilgrimage to the naturalistic freshness of the Himalayas. Even the Confucianist Chinese painter succeeds in conveying the values of his art only, he tells us, by becoming the naturalistic object which is bamboo.

For all these Orientals-Hindu, Buddhist, Taoist, and Confucian-alike, humanistic and cultural values are good to the extent that they conform to nature and the naturalistic differences of men. Furthermore, man prevents even these cultural norms from becoming dead, mechanical rules devoid of the spirit which sustains them only by immediate apprehension of, communion with, and return to the all-embracing immediacy of nature which is their source. It is not an accident in the philosophical tradition of India that one of the earliest bodies of written treatises, upon which the later Upanishads and the even later philosophical systems are largely commentaries, are called $\bar{A}$ ranyakas or forest treatises. Only by returning from the man-made normative ethical and legal conventions of cultural and social organization to the non-man-made pristine freshness and absoluteness of the primeval forests and nature can man find the source in which the ethical norms and institutions find their objective validation and from which they derive their spiritual vitality.

5. Id. at 451 .

6. Marcel Granet, La Pensée Chinoise (1934). 
The Rig-Veda is the oldest book of Aryan civilization, East or West. Professor N. G. D. Joardar, in his lectures in the Yale Law School on the nature and background of the traditional law of India, has pointed out that there are in this Rig-Veda twenty seers or sages who describe the nature of legal rules or norms and the source of their validation. The basic common thesis is that law, called rita, has its basis in, derives from, and in fact is the source of the cosmic order of nature. To be sure, for some of them this law is prior to the natural cosmic order. Even so, the law which is the true rule for men to use in ordering their man-made cultural institt1tions is derived from the order of non-man-made cosmic nature.

These early seers of the Rig-Veda go even further, distinguishing the normative law for society, called vrata, from natural law called rita, and adding that vrata has its source and validation in rita. In fact, it is from rita that vrata or dharma, that later Sanskrit word for law, derives. In his treatise on the Ancient and Medieval Religious and Civil Law of India, Pandurang Vaman Kane writes: "The idea of Dharma took the place of the very ancient conception of rta. In the Rgveda rta denotes the supreme transcendental law or the cosmic order by which the universe and even the gods are governed. . . ."7 He then quotes with approval Berolzheimer's statement ${ }^{8}$ that vrata and dharma are "derivatives" from rita.

The ancient seers of India made another distinction between vrata or dharma and smrtis or samaya. The smrtis express the positive law and commentaries of tradition; samaya refers to the more recent usage or conventions. Thus the smrtis and samaya refer to the positive and living law of society as it is in fact. For this reason, while suggestive with respect to legal norms, they cannot be taken as authoritative; in fact, they may be evil because, being man-made, they may derive from a conception of nature and natural man which is false. Thus P. V. Kane writes: "The smrtis are composed by human authors and so have no independent authority in matters of dharma, as a man may say what is either false or mistaken." Vrata, on the other hand, because it derives from $r t a$ which is verified against nonman-made nature, provides an ethical and legal "ought" against which the cultural "is" of sociological jurisprudence as described by smrtis and $s a$ maya can be judged. In short sociological jurisprudence, restricted as it is to the cultural "is," gives trustworthy norms only to the extent that it embodies a true or verified conception of nature and natural man.

The same naturalistic criterion for personal and legal norms appears after the Rig-Veda in the most important of all legal books in India, the book of Manu. Its conception and specification of personal domestic and legal norms still operate all over India. Although probably edited in its

7. Kane, 3 History of Dharmasastra $244-45$ (1946). 1912).

8. Berolzheimer, The World's Legal Philosophies 37-8 (Jastrow's transl,

9. KANE, op. cit. supra note 7, at 829. 
present form in the period between the second century B.C. and the second century A.D., it is continuous with the earlier tradition of the Rig-Veda. It does not surprise us, therefore, that the legal tradition of Manu begins with cosmology and the philosophy of nature and then refers all norms to this naturalistic source for their validation. ${ }^{10}$

\section{The Ethical and Legal Method of the Classical West}

It is well known that the technical terminology used even today in every law school in the Western world was created when Western law was made a science by those Roman jurists of whom the Scaevolas were the leaders. A. Vernon Arnold in his classic treatise, Roman Stoicism, has made it clear that most of the Romans who created Western legal science were Stoic philosophers. It is a commonplace of Stoic philosophy that the good is defined as conformity to the philosophy of the true for nature.

It is another commonplace of this scientifically formulated Roman law with its abstract technical legal concepts, that the legal norms which it regarded as valid for all men were called the jus gentium. At the beginning of his Inistitutes, Gaius writes as follows: "Every human community that is regulated by laws and customs observes a rule of conduct which in part is peculiar to itself, and in part is common to mankind in general. The rule of conduct which a people has settled for its own observance, and which is peculiar to that people, is termed the jus civile. Those principles which natural reason has taught to all mankind, are equally observed by all, and collectively are termed the jus gentium."

It is to be noted that the criterion for distinguishing the local provincial legal rules of the $j u s$ civile, from the universal legal norms valid for all men of the jus gentium, is "natural reason." Moreover, natural reason was not regarded as a priori. As will be shown in the sequel, it was defined by scientific methods which proceed from directly given data to deductively formulated scientific theory. In other words, it is reason applied to the facts of nature, which provides the criterion for universally valid ethical and legal norms.

The point in part is that, whereas men live in different cultures which generate the relative and often conflicting ethical and legal norms of the differing instances of $j u s$ civile, all men in the different cultures nonetheless live in the same nature. Consequently, whereas the derivation of ethics from a philosophy grounded in the humanities of the differing cultures vill lead to the pluralism and relativity of ethical and legal norms of the jus civile, an ethics derived from a philosophy based on nature alone gives the ethical and legal norms universally valid for all men of the naturalistic jus gentium.

10. The Laws of MIANu, 49 Sacred Books of the East cc. I, II (F. Mfas Mfüller ed. 1886).

11. Nasmith, Outline of Roman History 200, 11 (1890). 
It is to be emphasized that the distinction between $j u s$ civile and jus gentium, while necessary, is not a sufficient criterion of the universally normative. There is more than one jus gentium. It is only the naturalistic $j u s$ gentium which gives ethical and legal codes that are universally valid. As Arthur Nussbaum has pointed out in his Concise History of the Lave of Nations, ${ }^{12}$ there are two different meanings of the jus gentinm in Roman legal science. The one we shall call the philosophy of culture or sociological jus gentium, the other the philosophy of nature or naturalistic jus gcntium. The sociological jus gentium of the Romans is determined by studying the de facto legal rules and conventions of diverse societies and abstracting from them those legal rules and conventions which all the de facto societies have in common. By this standard slavery would be a normative good in society since every society known in Roman times contained slaves. There was, however, for Roman law another jus gentium derived not from that which is universal in the sociological "is" of different societies and cultures, but from the empirically verified science and philosophy of nature. It is only by the latter naturalistically grounded philosophical basis for ethical and legal norms that the Romans arrived at the theory that slavery, although universally present originally in every de facto society, is nonetheless evil. If status in nature rather than in the universal sociological "is" common to all de facto societies defines the good for men, then, since a slave is as genuine a creature of nature as is the head of an aristocratic family, status under the law must center in being a citizen of nature rather than a citizen of a proper aristocratic family and justice under such a law becomes the same for the slave as for the paterfamilias.

To be sure, this rule in ancient Roman times was followed more in principle than in fact, as is the case even today in the Dixiecratic portion of the United States. Nonetheless, even then, the norm against slavery was established as a principle, never again to lose its force as a norm in the Western world. Furthermore, an examination of the "Institutes" of Gaius will show that its codes make use of this naturalistic concept of legal status and citizenship to bring many people who were previously slaves under the protection of the law and into the legal status of free men in the Roman families.

These experiences of the Romans are illuminating with respect to certain contemporary suggestions for determining universally valid ethical and legal norms. Recent investigations by cultural anthropologists and sociologists have revealed the relativity and diversity of ethical and legal norms in the different nations and cultures of the contemporary world. The ideological conflict between the Soviet Russians and the traditional Western democracies underlines this fact. One suggestion offered by many contemporary social scientists for finding the universal common ethical and

12. Nussbaum, Concise History of the Law of Nations 19 (1947). 
legal norms necessary to build an effective resolution of the international disputes by legal rather than by warful means is to seek out the common factors in the diverse national and cultural legal codes and social norms. Such an investigation would give us the kind of universal norms the Romans had in their sociological jus gcntium.

Such a sociological jus gentium has two weaknesses, however, as a criterion of universal ethical and legal principles. The first weakness is that the common factor in the diverse norms of different nations and cultures is too weak to provide an effective norm for settling disputes. For example, the issue between Russian Communists and American New or Fair Dealers, which threatens the peace of the contemporary world, turns around . the economic, political and other rules for human relations in society with respect to which the Americans and Russians differ, not around the norms which they have in common. The second weakness in the universal common norms of sociological jurisprudence is that the de facto legal norm common to all societies and cultures, even were it not weak, is not necessarily good. The universality of slavery in every legal system at the time of the Romans is a case in point.

The latter consideration indicates that an adequate ethical and legal science must have a jus gentizm with its foundations outside the de facto ethical conventions and codes of the humanistic sociological jus gentium; otherwise there is no basis under any circumstances for judging the status quo sociological "is" to be bad. The only source for norms other than those of the sociological "is" of culture is nature. It was precisely for this reason that the Roman Stoic philosophers who created the Western science of law distinguished the sociological jus gentium from the philosophical naturalistic jus gentium and affirmed that only the latter jus gentium is the criterion of the good and the just. Hence, the well-known dictum of Roman legal science that jus gentium is grounded in jus naturae.

It appears, therefore, that the ethical and legal methods of the traditional Orient and the classical West are identical. Just as the Vedic and Upanishadic law, which forms the customs of India to the present moment through the persisting influence of the codes of Manu, distinguishes the sociological "is" of de facto custom, called samay'a, from the normative "ought" of vrata and declares that vrata, which designates the normatively good and just derives from rita, the law of nature; so the Roman foundations of Western legal science distinguish the jus civile of local, relativistic de facto positive legal codes and customs from the jus gentium, and within the jus gentium distinguish the sociological jus gentium of those codes common to all de facto societies from the naturalistic philosophical jus gentium which alone specifies the criterion of the universally good and just because it is grounded in jus naturae.

In the classical West, it was not merely the Roman Stoic philosophers, who were the creators of the Western science of law, who used this method. 
A. Vernon Arnold has made it unequivocally clear that every school of Greek philosophy-Zenoian Stoics, Platonists, Aristotelians and Epicureans-used the same method. ${ }^{13}$

Of Zeno, the founder of the Greek Stoic School, Arnold writes: "The ideal state must embrace the whole world, so that a man no longer says, 'I am of Athens' or 'of Sideon,' but 'I am a citizen of the world.' Its laws must be those which are prescribed by nature, not by convention."14 Arnold continues, "Zeno, after writing his Republic, . . . could not, perhaps, avoid noticing that the coming of his model Kingdom was hindered by the narrowmindedness of the philosophers, their disagreement with one another, and their lack of clear proofs for their dogmas. He began to realize that the study of dialectics and physics was of more importance than his Cynic teachers would allow; . . . From this time he no longer restricted his outlook to force of character, but sought also for argumentative power and well ascertained knowledge. The foundations of his state must be surely laid, not upon the changing tide of opinion, but on the rock of knowledge."15

Platonists, Aristotelians and Epicureans used the same method. "It was," continues Arnold, "a common complaint of [the Aristotelians] that the Stoics had stolen their doctrines wholesale and had altered their names only."18 Of the Epicureans and Stoics, Arnold adds: "Both founded, or conceived that they founded their ethical doctrine upon physical proofs; that is, both maintained that the end of life which they put forward was that prescribed by natural law. As a consequence, they agreed in removing the barrier which Socrates had set up against the pursuit of natural science."17

Apparently Socrates reached the same conclusion before he died. Otherwise it is difficult to believe that Plato in Book VII of the Republic would have put the following words into the mouth of his beloved Socrates: "But I must also remind you, that the power of dialectic alone can reveal this, [the idea of the good] and only to one who is a disciple of the previous sciences."18 If one turns back a few pages in the Republic, where the description of these previous sciences appears, one will discover that everyone of them is a mathematical natural science. This means that the later Socrates, if Plato's description of him can be trusted, believed that the ethical norms for human conduct and legal institutions must be verified against the experimentally verified theories of mathematical natural science when the latter theories are analyzed by the method of dialectic to bring out their

\footnotetext{
13. Arnold, Roman Stoicisar (1911).

14. Id. at 66 .

15. Id. at 67.

16. Id. at 64 .

17. Id. at 74 .

18. The Republic of Plato, Bk. 7, line 534, p. 236 (B. Jowett ed. 1888).
} 
epistemological assumptions and the attendant theory of natural man as a mind or knower which they entail.

Nor is it difficult to find the reason why Socrates changed his mind about the method of ethics in the later portion of his life. As A. Vernon Arnold has made clear, the attempt of the early Socrates to ignore the philosophy of nature and set up ethics as an independent subject, appealing to the facts of intuitively given conduct and of the intuitively given humanistic values of culture for its validation, led to the ethical relativism of the Sophists and the cultural relativism of the jus civile. It led also to the skepticism about the possibility of validating ethical norms that produced the Cynics. In short, Socrates, in the early portion of his life, tried out the non-naturalistic method for validating ethical norms, pursued by some modern philosophers since the time of Kant, and found it to end in failure.

The later Socrates, and all subsequent schools of Greek philosophy-the Zenoian Stoics, the Platonists, the Aristotelians and the Epicureansbrought physics and the philosophy of natural science back into ethics as basic. Forthwith for all schools of Greek and Roman philosophy, ethics is the philosophy of natural science applied. As $\mathrm{H}$. Rackham writes in his "Introduction" to Cicero's De Natura Deorum, "In spite of the strong antagonism between the Epicureans and the Stoics, their doctrines had features in common which indeed characterized all the thought of the period. From Aristotle onward Greek philosophy became systematic; it fell into three recognized departments, Logic, Physics, and Ethics, answering the three fundamental questions of the human mind: (1) How do I know the world? (2) What is the nature of the world? (3) The world being what it is, how am I to live in it so as to secure happiness?'10

The character of logic as conceived by all these schools of Greek philosophy, which came to expression in Roman Stoicism, is described in detail by Arnold. ${ }^{20}$ He makes it clear that logic-the first branch of philosophy - 'is subdivided into 'dialectic,' which deals with reasoning, and 'rhetoric,' the art of speech."' Dialectic includes the specification of the epistemology of knowledge and the inductive methods by which the content of knowledge of nature in physics is obtained as well as the rules of syllogistic deductive reasoning. It is to be emphasized that reason is never conceived by any of these Greek or Roman schools as a priori. It starts, instead, with data given empirically through the senses. Of sensations, it is affirmed that they are always true. Only propositions, because they are constituted of ideas referring to "mind-pictures," are sometimes true, sometimes false."2

What is most interesting of all is that the definition of $\sin$ (aнаргіa)

19. Rackhay, Introduction to Cicero's De Natura Deorux vii (The Loeb Classical Library ed. 1933).

20. ARNold, op. cit. stipra note 13, c. VI.

21. Id. at 129 .

22. Id. at 131. 
appears at the very beginning of inductive logic before one arrives at deductively formulated scientific theory with which the later stages of epistemology, scientific method and dialectic are concerned. Sin is defined as assent to false propositions about inductively given data of natural science. ${ }^{2 y}$ Assent is wrong when it is based merely on "mind pictures" alone rather than on "mind pictures" that are verified against inductively given knowledge. In other words, sin is assent to false propositions concerning the empirically verified factors of nature and the natural man or refusal to assent to such empirically verified propositions. This puts in very precise terms the thesis that the criterion of virtue and $\sin$ for culture and cultural man is the empirically verified criterion of the true and false for nature and natural man.

By nature and natural man is meant any and all facts concerning either which is not in part at least an effect of the beliefs of men. By culture and cultural man is meant any artifacts, i.e. facts which are in part at least what they are because of behavior resulting from the beliefs of men. Natural facts, not being man-made merely are; they are neither good nor bad any more than they are true or false. Only artifacts, because by definition they are man-made, deriving from beliefs of men which are true or false to natural facts, can be good or bad. Moreover, cultural facts are good or bad solely because the propositions concerning natural facts from which they derive are true or false.

This theory of ethical verification has the merit of providing a meaning for $\sin$ in the methodology and science of nature. Certainly any moralist wants to brand as sinful an untruthful report of facts by any natural scientist. This definition of the Greek and Roman philosophers accomplishes such a purpose.

Although a meaning for $\sin$ is provided by the Greek and Roman philosophers in the preliminary inductive methods of natural science, these methods do not provide a sufficient criterion of virtue. One can sin by falsely reporting a solitary inductively given fact. To have virttue, however, according to the Greek and Roman criterion, one must be truthful not merely about piecemeal facts in isolation, but also about all the intuitively given facts in their relations to one another and to the whole. For this reason, virtue requires the methods of deductively formulated scientific knowledge of the latter stages of scientific inquiry as well as inductive methods of the earlier stage. ${ }^{24}$ One can sin by the false reporting of data given by inductive methods. One cannot, however, obtain virtue by purely inductive methods. To obtain virtue, one must have systematic knowledge taking all the inductively given facts concerning nature and human nature into account in a single consistent theory. This is the meaning of the dictum

23. Id. at $132-33$.

24. For a detailed account of the different stages of scientific inquiry and their respcctive scientific methods, see my LSH, sipra note 1, cc. I-XII. 
of all the schools of Greek and Roman philosophy that "virtue is knowledge in the light of the whole."25

Because dialectic includes epistemology as well as the specification of the successive inductive and deductive scientific methods for knowing natural facts, it is not the empirically verified deductively formulated scientific theory in the form in which it comes from the scientist that alone provides the criterion of the good. In addition the method by which the theory is verified must be analyzed to bring out the relation between the technical concepts of the theory and directly inspectable data, thereby revealing its precise epistemological meaning. When this is done for any verified scientific theory of nature, an entailed theory of man as mind or knower is given. Thus any scientifically verified theory of nature turns out under methodological and epistemological analysis to be as much a verified theory of the knower, his knowing, the meanings involved in his knowing, and, hence of mind, as it is a verified theory of nature.

Nor should there be any surprise over this. For every successfully verified theory of nature is as much a verified instance of mental activity and human knowing as it is an instance of a verified theory of nature. Failure to note this is the major error of those who affirm that a philosophy of natural science and its ethics of natural law ignore human nature. But conversely, failure to realize that before scientically verified theories of natural man and nature exhibit their implications for ethics, they must be analyzed to bring out their epistemological meaning with respect to the nature of man as a mind and knower, is the equally frequent error of many contemporary scientists and philosophical naturalists when they turn to ethics.

It is scientifically verified theory of natural man and nature (1) in the light of all the facts about both, not merely about some facts, which is (2) analyzed methodologically and epistemologically to bring out the type of mind, meanings and modes of knowing required to arrive at its basic technical concepts, not merely the verified scientific theory unanalyzed, which is the criterion of the good and the just for the artifacts which are culture and cultural man. It is because all the facts, as far as it is humanly possible to obtain them in a single theory at any stage of human history, not merely some facts, are required that the Greeks specified virtue to be not conduct in accord with knowledge of one particular fact about nature and human nature, but knowledge in the light of the whole. It is because even systematically verified scientific theories which aim to include within themselves all the facts must be analyzed methodologically and epistemologically to bring out the nature of natural man as a mind and as a knower, that the Greeks, with the later Socrates, added that the idea of the good is to be found only by applying dialectic (i.e. methodological and epistemological analysis) to the hypotheses of the verified natural sciences.

25. Italics mine. See ARNold, op. cit. supra note 13, at 140 . 
A crucial question remains for consideration : If both traditional Oriental and traditional Occidental philosophy have the same naturalistic method for verifying personal and legal norms, why is it that the different traditional Oriental and Occidental philosophical systems produce different and often conflicting personal and legal normative prescriptions? This question has two answers, both of which are rooted in the epistemology of natural knowledge. We can merely state the answers here. Reasons for believing the answers to be correct will be found elsewhere..$^{20}$

One reason for the difference in ethical norms between Oriental and Occidental philosophy, notwithstanding the fact that both appeal to nature for their verification, is that Oriental science and philosophy in their appenl to nature tend, for the most part, to restrict knowledge of nature to entities and relations which are known by immediate apprehension directly; Western science and philosophy on the other hand introduce inferred theoretically designated entities and relations, the existence of which is verificd empirically only.indirectly by way of consequences deduced from the postulated unobservable system of entities. When ethics is interpreted as the philosophy of nature applied, it follows therefore, since nature, as immediately apprehended and described after the manner of Oriental philosophy, is different from nature, as theoretically designated after the manner of Western science and philosophy, that conduct and legal norms proceeding from these different philosophical conceptions will be different also.

In Chapter XII of The Meeting of East and West reasons have been given for holding that nature involves both of these factors and that the Oriental philosophical conception of nature is quite compatible with the Western philosophical conception. From this it follows, according to the aforementioned theory of ethical verification, that an adequate ethics not only can consistently, but must combine the ethical implications and applications of Oriental natural philosophy with those of Western philosophy. The fact, therefore, that there are differences in ethical values between Occidental and Oriental systems is an argument for rather than against this naturalistic method of ethical verification.

Differences in the philosophy of nature may, however, have another source. If, as is the case in Western science, nature as designated by its verified theory cannot be deduced from immediately apprehended data but must be determined by a trial and error postulation by the theoretical imagination which is only indirectly verifiable by way of its deductive consequences, then quite reasonable scientific and philosophical students of nature, using empirical verification for their criterion of truth, may arrive, especially at different periods of history, at different postulated theories of natural man and nature. It will follow then, if ethics is but verified naturalistic philosophical theory applied, that the different Western epistemo-

26. NoRTHRop, MEW, supra note 1 ; Dorsey, supra note 4. 
logical philosophies of nature will have different ethical and legal norms, as is the case with the natural philosophy of Plato, Aristotle, Locke, Hume, Kant, Marx and Cassirer to mention but a few.

Even so, the contemporary scientific theories of Einstein and Schroedinger have a greater capacity to take care of all the inductively given facts than do the scientific theories of Locke, Newton, Aristotle or Plato. Consequently, if we are to be true to the dictum of our classical method that "virtue is knowledge in the light of the whole," it is the verified scientific theories of Einstein and Schroedinger rather than those known to St. Thomas, Locke, Hume and Kant to which we must apply dialectic.

It has become increasingly evident recently also that the epistemology entailed by Einstein's and Schroedinger's verified theories is not that of St. Thomas, Aristotle, Locke, Hume or Kant. Albert Einstein himself has made this clear. ${ }^{27}$ Henry Margenau has more recently made it abundantly evident in great detail. ${ }^{28}$ Even former positivists such as Herbert Feig ${ }^{29}$ now see that experimentally verified contemporary science entails an epistemology different from that of Hume and the earlier positivists. There are ample signs that philosophers of science approaching the contemporary problem of their subjects from many diverse philosophical standpoints-investigators such as Einstein, Cassirer, MIargenau, the writer and Feigl, to mention but a few, are coming to agreement on the epistemology of natural science and natural man as knower which the verified theory of contemporary natural science entails. It follows if we are to be true to the classical dictum for ethical verification that virtue is not merely knowledge in the light of the whole but also such knowledge subjected to the epistemological analysis of dialectic, that it is this contemporary epistemological philosophy of twentieth century verified systematic theory in natural science which must be our criterion of universally valid ethical and legal norms for our world. The good society for the world then becomes conceived as the one which permits this particular philosophy of nature and natural man as knower to come to expression.

As previously noted, this contemporary empirically verified philosophy of natural science provides a basic place for the directly verified factors in man and nature that came to fulfillment best in the naturalistic philosophy, ethics and law of the Orient, as well as for the theoretically designated, indirectly verified component of natural man and nature which finds its highest manifestation in the deductively formulated experimentally verified science, philosophy of science, ethics and law of the West. It follows that such a norm for one world not only ought to be, if the traditional criterion of the

27. See Northrop, Eirstein's Conccption of Science, supra note 2.

28. ILARgenaU, op. cit. supra note 2 .

29. Feigl, Existential Hypotheses, 17 Purcosopuy of ScIence, No. 1 (Jan. 1950); Logical Reconstruction, Realism and Pure Scmiotic, 17 Pmizosopuy of ScIEnce, No. 2 (April 1950). 
normative in both the Orient and the Occident is the correct one, but also can be. It can be because in its content as well as in the method for determining ethical and legal norms upon which it rests, it gives expression to the traditions each at least some twenty odd centuries old of the two major civilizations of our world.

In his Fundamental Principles of the Sociology of Laze ${ }^{30}$ Ehrlich tells us that any new positive law to be effective must conform to the underlying living law. It appears that the empirically verifiable universal, and hence truly international, positive legal norm to which our inquiry has led us has sufficient sources in Twentieth Century natural science to prepare mankind to understand and deal with the realities of an atomic age, and at the same time, because of its methodological roots in our world's oldest major traditions, meets Ehrlich's crucial test for effectiveness.

\section{Implications for International Law}

The relevance of the foregoing analysis for international law can now be specified. Ehrlich has made it clear that any positive legal institutions which are to be effective must be grounded in the underlying cultural values of the living law. This means that an effective international law cannot be based on the economic, political, legal and other cultural practices of any one nation in the world, but must be rooted instead in the diverse ideologies and cultural traditions of its many nations and peoples. In an age such as our own in which the political focus of the world has shifted from Western Europe to Asia, this must include the Orient as well as the modern West. Hence, before a more effective international law can be obtained an objective study must be made of the positive legal codes and procedures and their respective underlying cultural and naturalistic philosophical foundations of the world's major nations and cultures.

In studying the positive legal practices and underlying cultural beliefs and habits of the Oriental peoples, one must direct attention to their character in ancient and medieval times before the influence of the West upon them. This is necessary because the Oriental peoples have revolted against a way of life based upon Western norms and institutions alone. All the peoples of Asia are insisting that any international policy, and hence any international law which has their support, must take the institutions, values and beliefs of the traditional Orient as well as those of the West into account. This makes it imperative in rooting contemporary international law in the living law of the peoples of Asia that one go behind Westernized Asia to the earlier Asian Asia.

When this is done, one finds that the different major peoples of Asia have positive legal codes and procedures and underlying naturalistically

30. Ehrlich, Fundamental Principles of the Socrology of Law (Walter L. Moll's transl. 1936). 
verified norms and practices of the living law in common. ${ }^{32}$ The same is true in lesser part, notwithstanding the contemporary ideological and behavioral conflict between the Soviet Communists and the traditional modern democracies, for the major peoples and nations of the West. ${ }^{32}$ The implications of these two facts for international law have been indicated by Gray L. Dorsey. ${ }^{33}$ It has been shown in addition that the common content of the living law of the major Oriental peoples and the common content of the traditional living law of the major Western peoples are both ultimate and compatible. ${ }^{34}$ This means that in content as well as in method, the two major traditional civilizations of our world already contain foundations in the world's living law for a more effective positive international law. We have but to take advantage of them.

What modifications in contemporary international law are required to take advantage thus of the existant de facto living law of the two major civilizations of our world? First the traditional international law which derives almost entirely from the philosophical beliefs and living law traditions of the later Medieval or early modern West must be superseded. Second the current attempt to create a new international law based either on the 19th Century Marxist ideology of the Russian Communists or on the 17th, 18th, 19th and 20th Century ideology of the French and British Socialists and the American Conservatives or New Dealers must also be transcended. The traditional procedure has already turned international relations into a "Cold War" for the minds of men and for the political direction of the nations which threatens the peace of the world. It also presents Oriental and Latin American peoples with the unsatisfactory alternative of accepting an international law and an international policy which fails to take their different cultural values and the content of their living law into

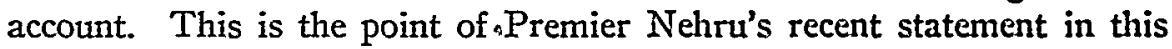
country to the effect that as long as his government represents the policy of his people, India will not take sides in the contemporary Western conflict between Marxist and non-Marxist Western doctrines, but will commit itself only to an international policy which takes the positive and living legal and cultural values of traditional India as well as those of the modern IVest into account.

The moral for effective contemporary international law is clear. It must face realistically the fact of cultural and ideological pluralism in the world and bring itself into accord with this fact. There are many living lawsOriental as well as Occidental; there is not onc living law.

Put more concretely, this means that before international law can become effective new principles must be formulated for it according to which

31. NorThrop, MEW, supra note 1, cc. IX-XI.

32. Id., c. VIII.

33. Dorsey, supra note 4.

34. NORTHROP, MEW, supra note 1, c. XII. 
no nation or people gains moral and legal status under international law unless they not merely insist upon the right to build their own cultural and legal institutions in the light of their own particular values and traditions, but also grant and respect in practice as well as in word the right of other nations and peoples to do likewise.

It might be thought that such a new international law would leave things as they are with no novel practical consequences. This, however, is not the case. Were this principle in effect, the present Russian Soviet government, for example, would not be able to gain status in any international legal body such as the United Nations unless it rejects its present explicitly written and practiced theory of international law. In an exceedingly important article on the Soviet doctrine of international law, Mintauts Chakste has demonstrated that according to this Soviet doctrine no nation has either moral or legal status under international law unless it builds its political and legal institutions upon Marxist Communist principles as interpreted by Lenin and Stalin. ${ }^{35}$ To accept the new basis for international law which our principle of pluralism in the world's living law prescribes, therefore, would have the very practical effect of putting an end to the contemporary farce in the United Nations in which the Soviet Russians have the privilege of belonging to a legally constituted international institution because they supposedly respect the rights of other peoples and nations to build their institutions in their own way, when in fact the Soviet Russians are required by their explicit doctrine of international law (to which unfortunately their speeches and behavior conform) to regard all peoples who order their lives on non-Marxist principles as behaving in an immoral and illegal manner.

This new basis for international law and its acceptance by the United States, for example, would also go far to put an end to the present weakness of national foreign policy in the contemporary world. This weakness arises from the fact that our policy has all too often presented itself to other peoples in Asia and Latin America and even continental Etrope as a program requiring them to conform to our legal norms, values and ideological traditions rather than to actualize their own. That the people of the United States when they reflect recognize the right of other people to build their law and their economic and other cultural institutions in their own way is not to be denied. This is of the essence of the doctrine of freedom of belief, discussion and religion which is fundamental to all our political institutions. To shift American foreign policy from a conception of international law emphasizing primarily American or even Western democratic values and traditions to one rooted in all the diverse values and traditions of all the nations and cultures of the world would foster, therefore, rather than hamper the basic values of our American tradition.

35. Chakste, Soviet Concepts of the State, International Laze and Sotcrcignty, 43 AM. J. INT'L L. 21 (1942). 
To make this tradition in foreign affairs effective, however, more than lip service must be given to the definition of a foreign policy and the construction of an international law which takes the legal practices and cultural traditions of all the nations and cultures of the world and not merely those of the United States or of Western civilization into account. The emphasis must be shifted from a study merely of the legal institutions and underlying cultural traditions of the United States or of British Common law to those also of the rest of the world. The focus of study in international law must be shifted from the national to the international standpoint. Students of international law must be as seriously concerned with the legal codes and underlying cultural practices and philosophical beliefs from which the codes derive, of ancient and medieval India, of Confucian, Taoist and Buddhist China, of Polynesian Asia and of Aztec and Inca as well as Spanish or Portuguese Latin America as they are with those of British and American common law and the Western legal and cultural traditions.

Nor can this inyestigation of the available grounds in the world's living laws for a more effective international law, to which our analysis has led us, stop with a mere determination of the positive legal codes and practices and their underlying living law content and beliefs of the major cultures and peoples of the world. One must also go behind the content and beliefs to the facts in nature which led initially to their verification and subsequent acceptance. This follows from our methodological principle that the method for verifying ethical and legal norms in the traditional Orient and the classical West is appeal to the facts of nature. It is at this point in the available living law grounds for a more effective international law that international sociological jurisprudence and the philosophy of the world's cultures passes over into naturalistic jurisprudence and the philosophy of the verified scientific theories of nature.

Without this passage from the basic living beliefs of a given culture, which as contemporary social science has demonstrated are always philosophical in character, ${ }^{36}$ and its attendant positive legal institutions to the facts of nature against which the basic philosophical beliefs were initially verified and are today verifiable, there would not be a way even in principle in international law of resolving international disputes arising out of a conflict of national and cultural norms. As the earlier sections of this paper have demonstrated, although the diverse peoples and cultures of the world differ in their living and positive legal norms, they all agree in their oldest and hence most established living law traditions, that the method for validating ethical and legal norms is by testing the basic philosophical conceptions of natural man and nature which they express against the facts of nature.

36. See Sororin, Soctety, Culture and Personaltry (1947); Kluckhohn, The Philosophy of the Navaho Indians in Ideological Differences and Wonld Order (Northrop ed. 1949); Sherif, An Outrine of Socral Psychology (1948). 
The basis for this is obvious. Although people live in different cultures with their differing and often conflicting living and positive norms, they nonetheless reside on the same planet in the same nature. This traditional common reference of the differing legal norms to nature provides, therefore, an effective criterion independent of these norms for judging between them and even reconciling them in cases of conflict. The naturalistic emphasis of our earlier analysis enables us, therefore, to see how under a new international law grounded in the fact of pluralism in the world's living laws, international disputes centering in a conflict of living legal norms between different cultures and nations can in principle at least be resolved.

Merely to shift the principles of international law from the battle between one or two major physically and economically powerful nations working for an international policy and law based on its particular legal norms and ideology to an international law grounded in ideological and living law pluralism would go far toward easing the present tension in the world. When to this is added the additional naturalistic method for settling international disputes arising out of the conflict of cultural or nationalistic living law norms, the constructive way to a more effective settling of international disputes by legal means is at least indicated.

$U_{p}$ to this point we have been considering the more specific implications of our earlier analysis for a more effective international law from the standpoint merely of grounding it in an understanding of the traditional living law and its underlying empirically verified philosophy of nature of the many traditional cultures of the world. It is an equally evident fact within the living law of our world that we live in an atomic age. It is equally well known that this fact is a consequence of the empirically verified theories of 20 th century mathematical physics. It follows that a positive international law which is to bring itself in accord with the living law of our time must draw upon the philosophy of this mathematical physics as well as upon the natural philosophy of the classical Greeks and Romans and the traditional Oriental sages. In short, the empirically verified philosophy of nature to which it turns for its content must be contemporary as well as traditional.

By combining the normative implications of the epistemologically analyzed philosophy of contemporary mathematical physics with the traditional ethical and legal norms of the empirically verified philosophies of nature of the traditional Orient and the classical West, ${ }^{37}$ we should gain the technical scientific concepts necessary to meet intelligently the economic and political needs of men the world over in an atomic age and at the same time draw to the maximum degree upon those factors in the diverse living laws of the two major civilizations of the world which have defined the traditional norms and values of mankind. An international law with such roots has a chance of capturing the hearts and minds of people the world

37. How this can be done consistently has been shown in principle in my MEW, supra note 1 , cc. XII, XIII. 
over since it is sensitive to and grounds itself in their respective indigenous norms and values. Any people or nation could put itself under such an international law with the confidence that in the practical adjudication of any dispute their own ways of life and values would be respected.

Such a new international law would be the most capable also of delivering on the frequent promises made to improve the economic conditions of men everywhere. Being sensitive to contemporary scientific knowledge and instruments, it would encourage a society which can surpass all others in efficiency. Finally, such a new international law should be effective in its moral controls over the otherwise ethically neutral scientific instruments. Being philosophically minded as well as empirically verified and scientifically grounded, it directs attention to and draws for its sanctions upon the moral, legal and religious norms, both traditional and contemporary, of men everywhere.

One caution should be noted in applying these principles for the guidance of international law to the contemporary foreign policy of any individual nation. The foregoing analysis was concerned with the question as to whether a more effective international law is possible and if so what the basis for it must be. It must not be assumed in judging the contemporary foreign policy of any particular nation that it should act as if the foregoing principles for international law and international relations were accepted today by all the nations of the world. Unfortunately this is not the case. As has been noted above, contemporary Soviet Russia believes in and operates upon the basis of an international policy which regards any other nation as immoral and evil and having no status under international law unless it builds its institutions on Marxist Communist principles as interpreted and applied by Moscow. Such belief and behavior are incompatible with the grounds for a more effective international law which we have indicated. It would be the utmost folly, therefore, from both a realistic and idealistic standpoint for any nation which made the aforementioned principles the touchstone of its own policy to act as if the other nations of the world are also acting on the same principles.

What then is any nation which sets the principles for international law and international conduct which we have specified as its standard and the world's standard for international conduct, to do in the face of the fact that one of the major powers in the world behaves and operates upon an incompatible basis and hence persistently with the intent of sabotaging such principles? Two procedures are obviously required in such a situation. First, one must root one's own policy and the justification for anything one does internationally upon the world-grounded rather than the nation-grounded principles which our analysis has indicated. Any nation which did this would immediately remove itself from effective attack by Communist propaganda which announces that this nation's policy is provincially nationalistic only and imperialistic. Second, any individual nation's foreign policy 
must at the same time face with complete realism the ideological doctrine and the behavior in accord with this doctrine of the Soviet Russians and act in the light of such an understanding.

There is no higher compliment that one can pay to any other nation, nor is there any more idealistic conduct with respect to any nation that one can pursue than to judge it from its own ideological standards. When one does this with respect to the Soviet Russians one notes immediately that it is an essential part of their ideology and hence of their culture and legal principles that ideas and ideals are not merely neutral but positively evil unless they are embodied in matter. This means that the Soviet Russians will have no real respect whatever for any nation or group of people such as the Wallaceite liberals and Quaker pacifists who act toward them as if they, the Russians, were nonmaterialistic idealists and pacifists who will respect ideas and principles of policy disembodied from all matter and military force.

It cannot be too strongly emphasized that any culture, people, person or nation judges others from the standpoint of its own philosophy and standards. In terms of the Russians this means that they will have no respect for any nation or people which does not embody its own standards and principles of policy in all the matter and force it can muster. It is not an accident that Russian policy, as Secretary of State Acheson has emphasized out of real experience with the matter, respects only a de facto state of force at a given place in the world which has to be reckoned with because it cannot be budged. This is a necessary consequence of the Marxist philosophy of dialectic materialism and the criteria of good conduct, moral and legal, which it prescribes. Practically this means that a national policy with respect to the contemporary Russians which is informed with respect to their ideas and ideals must confront their ideology with the aforementioned world ideology backed by force.

In short, a sound foreign policy must ground itself in the principles of a truly world ideology outlined in this paper while at the same time confronting Soviet ideology and policy with the force necessary to restrict it to those people who want to be Communists. Only in this way, the Communist doctrine and deeds being what they are, will other people have the chance to reach their moral, social and legal norms in their own way. Only thereby also will the universal moral and legal norms which this paper has indicated to be valid have a chance to come to expression in the world. 